\title{
AC 2009-1404: "REAL OUTREACH EXPERIENCES IN ENGINEERING": MERGING SERVICE LEARNING AND DESIGN IN A FIRST-YEAR ENGINEERING COURSE
}

\section{Christopher Williams, Virginia Tech}

Christopher Bryant Williams is an Assistant Professor at the Virginia Polytechnic Institute \& State University with a joint appointment in the Mechanical Engineering and Engineering Education departments. Professor Williams is the Director of the Design, Research, and Education for Additive Manufacturing Systems (DREAMS) Laboratory. His joint appointment reflects his diverse research interests which include design, methodology, layered manufacturing, and design education.

\section{Richard Goff, Virginia Tech}

Richard Goff is an Associate Professor and Assistant Department Head of the Department of Engineering Education in the College of Engineering at Virginia Tech. He is also the Director of the Frith Freshman Engineering Design Laboratory and the Faculty Advisor of the VT Mini-Baja Team. He is actively involved in bringing joy and adventure to the educational process and is the recipient of numerous University teaching awards.

\section{Janis Terpenny, Virginia Tech}

Janis Terpenny is an Associate Professor in Mechanical Engineering and Engineering Education, and an affiliate faculty of Industrial \& Systems Engineering at Virginia Tech. She is Director of the Center for e-Design, a multi-university NSF I/UCRC center. Her research focuses on methods and representation schemes for early design process and on engineering design education. She was previously faculty at the University of Massachusetts and worked at General Electric (GE), including the completion of a two-year management program. She is a member of ASEE, ASME, IIE, and Alpha Pi Mu and is the Design Economics area editor for The Engineering Economist and the Associate Editor for the ASME Journal of Mechanical Design.

\section{Jenny Lo, Virginia Tech}

JENNY LO is an advanced instructor in the Department of Engineering Education at Virginia Tech. She has primarily been involved in teaching first-year engineering classes, and her research interests include first-year engineering curriculum, engineering ethics instruction, and student diversity.

\section{Tamara Knott, Virginia Tech}

Tamara Knott is an Associate Professor in Engineering Education at Virginia Tech. She focuses on pedagogical issues associated with teaching freshman engineering. She is the course coordinator for the second semester Exploration of Engineering Design course taken by approximately 900 freshman engineering students each spring.

\section{Karen Gilbert, Virginia Tech}

Karen Gilbert is the Assistant Director of the Center for Student Engagement and Community Partnerships and the Coordinator of VT-ENGAGE at Virginia Tech. The Center is devoted to being a hub for student engagement with non-profit organizations, civic groups, schools, and community agencies across the Commonwealth of Virginia and beyond. VT-ENGAGE provides the resources and links for the Virginia Tech community to find a place to volunteer their time, talents and energy and make a difference in the community. 


\title{
"Real Outreach eXperiences In Engineering": Merging Service- Learning and Design in a First-Year Engineering Course
}

\begin{abstract}
The instructors of the first-year engineering course at the Virginia Polytechnic Institute and State University are faced each year with the challenge of providing a meaningful, appropriate, and valuable project experience that supports learning and fosters interest about engineering design. While past projects have been suitable for achieving basic learning outcomes, the speculative nature of these projects has not provided opportunities for student learning on broader topics such as working with a customer, identifying customer requirements, framing an open-ended design problem, and most importantly, identifying their role as an engineer in the world at large. In the spring semester of 2008, the instructors of "Exploration of Engineering Design" explored the use of a project set in the context of service learning as a means of achieving these broader learning objectives while still meeting the course learning outcomes for engineering design. The ROXIE Program (an acronym for "Real Outreach eXperiences In Engineering") was born from this effort.

With the aid of the campus's Service Learning Center, 179 teams (composed of 4-6 students each) were paired with non-profit community organizations. The student teams acted as "Systems Design Consultants" and were instructed to "serve and improve" the community through engineering design. Specifically, the teams were tasked with (i) performing an act of service for the community organization, (ii) meeting with the community organization's leader to identify a design problem that needed to be solved, and finally, (iii) proposing a solution to the identified problem by following the design method taught in class.

In this paper, the authors will describe the rationale, pedagogical choices, and administrative tasks involved in providing a design-related service learning experience for first-year students on such a large scale. Excerpts from students' reflection essays are presented as anecdotal evidence that the proposed program assisted students in achieving the course objectives and learning outcomes.
\end{abstract}

\section{Offering a First Year Engineering Design Experience on a Large Scale}

\subsection{Context: "Exploration of Engineering Design"}

The context for this paper is a required introductory course for first-year engineering students of Virginia Tech. Virginia Tech is a large mid-Atlantic land-grant university; the engineering college is its largest, and features an undergraduate enrollment of $\sim 6,000$ students. The twocredit course, entitled "Exploration of Engineering Design" (ENGE 1114), features an enrollment of over 900 students, is segmented into multiple sections, and is structured around two weekly meetings: one large ( 300 seat) one-hour lecture that is orchestrated by the faculty instructors, and one two-hour workshop session ( $\sim 35$ seat) that is monitored by a graduate teaching assistant and typically features hands-on activities. 
Students enrolled in this course have yet to formally declare the engineering discipline in which they will specialize. At this point in the first-year program, the students enrolled in ENGE1114 have only decided that they do not wish to study Computer Science or Electrical \& Computer Engineering; there is a separate introductory class devoted to these two disciplines. From a broad perspective there are three student archetypes at this stage in the first-year program:

- Some students are certain of which engineering discipline they will study and have begun identifying themselves as a member of their relative discipline communities.

- Others students are certain that they want to continue studying engineering, but are uncertain of which discipline to choose.

- Many others are undecided on whether or not to enter the engineering field.

In this regard, the course features a multidisciplinary group of students with a diverse scope of interests.

Due to these diverse interests, the course's primary learning objective is broadly formulated so that the course content is of relevance to all engineering disciplines. The primary objective, for students to gain an understanding of the engineering design process, is presented via three separate content modules:

- Design Methodology: Students learn how to systematically address an open-ended design problem by learning project management techniques, structured concept generation and selection methods, and design communication principles.

- Graphics Communication: Students learn how to graphically communicate their design ideas through lessons in reading engineering drawings, computer-aided solid modeling, and sketching and visualization techniques.

- Programming: Students learn more about structured problem solving techniques through lessons in algorithm development. Students are also introduced to basic programming. principles such as syntax, decision structures, and looping structures.

In addition to homework, quizzes, and exams, students' understanding of course content is assessed through a semester-long design project. The design project not only provides an opportunity for students to engage in engineering design; it also serves as an opportunity for students to synthesize the separately presented course content modules.

\subsection{Objectives for a First Year Design Experience}

The instructors of "Exploration of Engineering Design" are faced each year with the task of designing a design project for their students. Specifically, they are challenged with providing students a meaningful, appropriate and valuable context in which to practice design that supports learning and fosters interest in the field. To guide their selection, the instructors have identified the following basic learning objectives of a successful design project:

Upon successful completion of the design project, the student will be able to...

- Demonstrate an understanding of the engineering design process.

- Demonstrate an understanding of project management methods.

- Communicate engineering information in formal written and oral reports.

- Participate in the successful completion of a major group design project. 
While these learning objectives provide general guidance in the development of a design project, they do not fully capture the challenges that are specific to developing a design experience for a multidisciplinary group of first-year engineering students. As such, the authors propose three requirements to be considered when developing first-year design projects:

- Avoid discipline centrism. Due to the diverse set of disciplines present in the course, it is necessary to avoid projects in which the solution lies entirely within the boundaries of a single engineering discipline.

- Emphasize the "Problem Definition" phase of design. The authors suggest that the project focus should be in the early stages of design (problem definition and conceptual design), as these skills are of vital importance to all engineering disciplines. The "problem definition" stage should especially be emphasized; the Boyer Commission on Educating Undergraduates in the Research University has recommended that students gain practice with problem definition skills within their first year ${ }^{1}$. The ability to frame and scope engineering problems is a stated educational outcome of $\mathrm{ABET}^{2}$. Furthermore, Friedman argues that the ability to properly scope problems will be a distinct competitive advantage for U.S. engineers in a globalized engineering economy ${ }^{3}$. Finally, the skills involved in the early stages of design are easily applied by first-year students. This is in contrast to the later stages of design (embodiment and detail design), as students have yet to complete an engineering analysis course and are thus not ready to apply and synthesize those skill sets in a formal engineering analysis. First-year design projects which focus in the later stages of design, such as "contraption building" design competitions, provide students an opportunity to gain experience in being creative with limited resources. However, it is the authors' experience that first-year students' attempts at the later stages of design tend to be more focused in "tinkering" than in a formal analysis, and thus, in the context of engineering design methodology, do not provide as significant of a learning opportunity. This is not to suggest that they are not capable of designing; firstyear students can have meaningful design experiences that are focused in problem identification and conceptual design as it introduces them to techniques that structure their creative thoughts ${ }^{4}$.

- Provide opportunity for the student to see the impact of engineering solutions. A broader project objective, the authors suggest that first-year students be given an opportunity in which they can associate the engineering field as one of service to the world at large. An ABET educational outcome ${ }^{2}$, understanding the impact of engineering design solutions is a pedagogical goal common to all engineering disciplines and has shown to increase retention of engineers in the first-year ${ }^{5}$.

These suggested considerations are meant to direct a instructor's project selection decision towards those projects which offer design lessons that are universal to all engineering disciplines (ability to scope a large problem; interpret needs from a customer; generate concepts; and make selection decisions), and are most appropriate for the first-year engineering student.

\subsection{Providing a First-Year Design Experience through Service-Learning on a Large Scale}

Past projects of "Exploration of Engineering Design" have been speculative in nature; students were given a design problem statement and had to speculate both the customers' needs and the context of the problem. For example, one semester project featured students designing and building devices capable of launching pumpkins. While such projects promote basic problem- 
solving and resource management skills, their limited context and concrete objectives did not provide a significant opportunity for the students to achieve all of the course's learning objectives (e.g., interpreting customer needs, managing a design project, framing an open ended problem, etc.). The instructors were also concerned that the projects' focus in machine elements and construction was not universally amicable to the students' varied engineering interests.

In an effort to meet the broad objectives detailed in the previous section, the authors look to service-learning as a framework for developing a design experience for a first-year engineering course featuring a large enrollment. In this paper, the authors describe the implementation of a service-learning themed design project in a first-year engineering course and provide insight into the challenges faced when implementing such a project on a large scale. The authors provide a review of service-learning and examples of its implementation in an engineering context in Section 2. In Section 3, the authors' efforts to merge service-learning with engineering design education are detailed. Specifically, the implementation of their course's design project, "Real Outreach eXperiences In Engineering" (ROXIE) is presented. Preliminary results from the first implementation of ROXIE are provided in Section 4 in the form of reflective feedback from community partners and students. Closure and thoughts on future work are provided in Section 5 .

\section{Service-Learning as a Method for Design Education}

The U.S. National and Community Service Trust Act of 1993 formally defined service-learning as "a method under which students learn and develop through active participation in thoughtfully organized service" 6 . The act also identified the following required additional criteria for servicelearning activities:

- The service must meet the needs of a community.

- Is coordinated with some educational program.

- Helps foster civic responsibility.

- Is integrated into, and enhances, the students' academic curriculum.

- Provides structured time for student reflection.

Student engagement in service-learning activities has resulted in positive impacts on retention, civic responsibility, personal development, and a deeper understanding of the subject matter ${ }^{7}$.

Service-learning activities are becoming more prevalent in engineering curricula as instructors discover that their pedagogical objectives of problem solving, working in groups, and experiential learning match well with the stated criteria of service-learning ${ }^{8}$. Furthermore, Duffy and coauthors suggest that service-learning team projects provide students an opportunity to learn and demonstrate ABET learning outcomes pertaining to teaming, communication, understanding the impact of engineering solutions, and the identification, formulation and solution of design problems ${ }^{9}$.

Engineering design is a natural opportunity for the insertion of a service-learning activity into curricula as it provides students an opportunity to gain experience in practicing design while simultaneously addressing a community need ${ }^{10}$. One example of such an infusion is in the EPICS Program at Purdue University where students are involved in long-term team-based 
design projects focused in designing solutions for non-profit community organizations ${ }^{11}$. Service-learning design activities are also appearing in several first-year engineering courses ${ }^{4,12-}$

14. In addition to the above mentioned benefits of service-learning activities, Hobson suggests that they fit well in first-year engineering courses as they provide an opportunity for the students to better understand the true nature of the discipline ${ }^{12}$.

\section{The "Real Outreach eXperiences In Engineering” (ROXIE) Project}

Similar to other service-learning engineering design projects, the "Real Outreach eXperiences In Engineering" (ROXIE) project partners student teams with non-profit community organizations and tasks each team to design a solution for a need of their respective community partner. From the students' perspective, the ROXIE project is composed of three main phases:

(i) Volunteer. First students perform an act of service for the community organization (e.g., stocking shelves of a food bank, construction of low-income housing, restocking library shelves, etc.) in order to understand the "customer's" needs and context.

(ii) Identify design problem. By reflecting on their volunteer activity, students identify a need of the organization for which a solution can be designed. The relevance of this need is verified by the leader of the community organization leader through a group meeting. It's relevance to the course goals is also verified by the successful completion of a proposal assignment.

(iii) Propose design solution. Finally, students propose a solution to the identified problem by following the design methodology taught in class.

As the need for first-year students to gain experience in the "problem definition" phase of design is one of the impetuses of the authors' decision to merge service-learning and design education (as described in Section 1.2), the ROXIE project is unique in that students are responsible for framing their own design problem.

The ROXIE project is also unique in its large scale setting. Most service-learning design experiences reported thus far in the literature are typically done in classes featuring up to 20 students ${ }^{12}$. The largest engineering design-themed service-learning experience reported in the literature is Purdue's EPICS program, which accommodates 250 students a year; however it is not accomplished in the confines of a class setting and has participants at various academic leves $^{13}$. In fact, it has been suggested that a major drawback of service-learning themed design projects is their large resource commitment, and thus, its inability to be implemented at a large scale $^{4}$.

Over 900 students ( 185 student teams) participated in the initial ROXIE project trial (2008 spring semester). As the "Exploration of Engineering Design" is offered during the fall, spring, and summer semesters, more than 1250 students participate in ROXIE each year. While this large enrollment offers a wonderful opportunity to make a large difference in the local community, it does provide logistical troubles during the project's implementation. In this section, the authors discuss their implementation of the ROXIE project and the means in which the challenges of offering a service-learning design project on a large-scale are handled. 


\subsection{Partnering with Campus/Community Outreach Office}

One of the most challenge aspects of developing a service-learning experience lies in establishing connections with local community organizations and identifying opportunities for collaboration. This is made even more difficult when over 900 students are to be involved in the experience. In order to lessen the burden of organizing such a massive outreach effort, the instructors of the course connected with their university's Campus/Community Outreach office, the Virginia Tech Center for Student Engagement and Community Partnerships ${ }^{15}$ (and in partnership with VT-ENGAGE ${ }^{16}$ ). Partnering with this office was crucial to the success of the ROXIE project. Leveraging the office's community connections is the only way in which over 175 projects with $\sim 90$ community organizations can be identified and managed.

Involving students in service is an increasing national trend at universities across the country as it provides a means for the campuses to connect to their respective communities and to promote strong life-long citizenship of service for its students. As such, Campus/Community Outreach offices are becoming more prevalent as a means for promoting and supporting volunteerism, institutionalizing engagement at the university, and supporting a full service learning program. These offices are intimately involved with the local community and are thus well connected to its non-profit organizations and their needs.

Once potential partners were identified, the instructors sent a memo to the community partners to provide them information about the project, its deadlines, its learning objectives, and the rationale for its creation (Section 1.2). For the instructors, it was vitally important that the community partners were aware that ROXIE was not to be considered simply a service project it was to be considered as an opportunity to receive a solution to a need that their organization faced.

\subsection{Project Kickoff}

The students' first exposure to the ROXIE project came through a special "Design Project Kickoff" event. Taking place in an evening time period typically reserved for common examination time, the event served as an information session, a motivational tool, and a means for establishing the context for the engineering design process, community service, servicelearning and outreach. Wary of potential student confusion or apathy that could accompany being involved in a large-scale project with a purposefully ill-defined starting point, the instructional team focused on instilling a sense of enthusiasm, excitement, and empowerment in the students.

In addition to providing an overview of the project and detailing the logistics of its implementation, the instructors spoke to the student audience about the services engineers provide to the community. Several guest speakers from the community shared moving stories and photos related to the vast array of community needs as a means of helping students to understand the potential impact of their project. Finally, speakers from the Center for Student Engagement and Community Partnerships provided students with special instructions on offcampus travel, safety, and professional behavior. 
In addition to the two one-hour sessions (each session featuring 500 students), students were given a written "Project Brief" that provided a written documentation of the project's overview, learning objectives, schedule, and grading information.

\subsection{Partner Selection}

The next implementation step was matching student teams with community partners. In an effort to increase student motivation and engagement, the instructors determined that it would be ideal to provide student teams the opportunity to select community organizations with which they were interested in assisting.

In order to provide an equitable opportunity for students to select a community organization at such a large scale (185 teams), an online signup process was used. A website was designed that allowed its users to select available partnerships from a drop-down menu. The list was created such that, once a partnership was selected by a team, it was dynamically removed from the list. The website went "live" at a predetermined time; thus allowing student/community partner matching to occur on a virtual first-come, first-served basis. Student team selections were based on their research of ROXIE community partner mission statements (provided prior to the virtual sign-up process).

\subsection{Project Proposal}

Once their community partner selection had been verified, student design teams could officially begin their semester design project. As the impetus of the project was in the "Problem Definition" phase of design, the students were responsible for identifying their own design tasks. As mentioned at the beginning of Section 3, students did so by first volunteering with the organizations to learn about their operations and needs. After the volunteer effort was completed, students met with their community partner to discuss opportunities for improvement through the implementation of the engineering design process.

To assist students with scoping their design project, the instructors provided three guiding questions:

- Is there an opportunity for improvement?

- Are there multiple requirements and/or constraints that must be met for a satisfactory solution to the problem?

- Are there multiple alternatives for a successful solution to the problem?

An appropriately scoped design project would enable the students to answer in the affirmative for all three questions. The students were then required to submit a written project proposal. In order to ensure that students had scoped a true design problem (and not simply a service opportunity), the proposal was reviewed by the teaching assistant who managed their respective workshop sessions.

\subsection{Design Methodology Instruction}

Once their proposal is approved, student teams begin working towards the creation of a design solution by following the systematic process taught in the class during the four-week design methodology module. Using the text authored by Dym and Little as a foundation ${ }^{17}$, the instructors educate students about the processes, frameworks, and tools that exist in the Problem 
Definition and Conceptual Design stages of a systematic design process. The content covered in this module is summarized in Table 1.

Table 1. Organization of Content Delivery for the ENGE 1114 Design Methodology Module

\begin{tabular}{|c|c|c|}
\hline Week & Large-Group Meeting Topic & Workshop Activity \\
\hline 1 & $\begin{array}{l}\text { Project Management and } \\
\text { Teaming }\end{array}$ & $\begin{array}{l}\text { Team-building activities: Student complete Myers-Brigg personality } \\
\text { tests and reflect on the results as a team. Student teams then compete in } \\
\text { a balloon tower building competition. Teams then begin drafting their } \\
\text { Code of Cooperation and their project Gantt Chart. }\end{array}$ \\
\hline 2 & Generating Requirements & $\begin{array}{l}\text { Generating requirements for products and processes: Students are asked } \\
\text { to identify requirements for a process ("design the perfect camping } \\
\text { trip") and a product (design a device to assist in hauling equipment on } \\
\text { trails). }\end{array}$ \\
\hline 3 & $\begin{array}{l}\text { Functions and Concept } \\
\text { Generation }\end{array}$ & $\begin{array}{l}\text { Functional decomposition: Students learn about function and means } \\
\text { through dissection of See-N-Say toys. }\end{array}$ \\
\hline 4 & $\begin{array}{l}\text { Alternative Generation \& } \\
\text { Selection }\end{array}$ & $\begin{array}{l}\text { Selection: Students learn about metrics and the selection decision matrix } \\
\text { through a paper airplane design competition. }\end{array}$ \\
\hline
\end{tabular}

The large-group meetings are focused in assisting students in gaining an understanding about the design methodology content. While the primary mode of instruction was lecture, Tablet PCs and their integrated feedback mechanisms are used to engage the students via activities such as sketching, ideation exercises, and polling. The workshop activities were designed to provide students an opportunity to gets hands-on experience in applying the "tools" of the design process (Figure 1) on controlled examples. The design project, and its associated deliverables (midterm report, final report, and final oral presentation), required students to apply their understanding of the content to an open-ended problem. Thus, design instruction in this module is organized to assist students in advancing their understanding through progressive cognitive levels: knowledge is gained through text reading, comprehension is gained through the context and examples provided in the lecture, application is provided via hands-on workshop activities, and analysis and synthesis are provided through the design project experience.

In order to guide the students through the open-ended nature of their design project, the instructors provided direct links between the phases of design (and its associated tools, Figure 1) and their ROXIE project (Table 2).

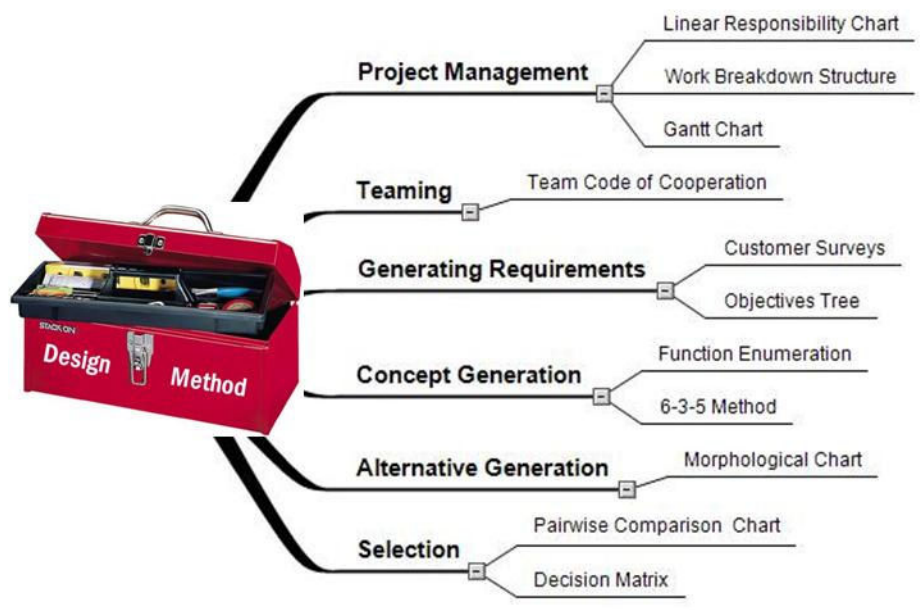

Figure 1. Design "Tools” Covered in ENGE 1114 
Table 2. The Phases of the Design Methodology and of the ROXIE Project

\begin{tabular}{|c|c|}
\hline Design Phase & Project Components \\
\hline Identify the problem & $\begin{array}{l}\text { - Partner with community service group } \\
\text { - Serve community group in order to better understand their needs } \\
\text { - Meet with community group leader(s) to identify specific needs and begin project } \\
\text { planning }\end{array}$ \\
\hline $\begin{array}{l}\text { Clarify the design } \\
\text { task }\end{array}$ & $\begin{array}{l}\text { - Draft project proposal (must be approved by instructor) } \\
\text { - Develop project plan (Gantt chart, Linear Responsibility Chart, Work Breakdown } \\
\text { - Structure, etc.) } \\
\text { - Identify problem requirements and constraints }\end{array}$ \\
\hline Conceptual design & $\begin{array}{l}\text { - Develop several alternative solutions to design problem } \\
\text { - Perform basic analysis of alternative solutions } \\
\text { - Select amongst alternatives to identify principal solution }\end{array}$ \\
\hline Preliminary design & $\begin{array}{l}\text { - Depending upon the type of design problem, this phase could consist of: } \\
\circ \text { Developing/constructing a functional prototype } \\
\circ \text { 3D modeling of a new component } \\
\circ \text { Developing a flowchart/algorithm and/or computer program for a new operation, } \\
\text { process, or procedure } \\
\circ \text { Preliminary programming of a new analysis tool } \\
\circ \text { Preliminary implementation of a new process/tool } \\
\end{array}$ \\
\hline $\begin{array}{c}\text { Design } \\
\text { documentation }\end{array}$ & $\begin{array}{l}\text { - Compose a report of project progress and develop a proposal for further implementation } \\
\text { of principal design solution } \\
\text { - Present project progress and proposal to peers } \\
\text { - Write reflective learning essay }\end{array}$ \\
\hline
\end{tabular}

Through the implementation of this projects, the students were able to gain first-hand experience in dealing with real (not speculative) customers, defining project objectives and constraints, generating design alternatives, and performing a systematic selection to identify the design alternative which best fit the community partner's needs. Due to the brevity of the semester (and the instructors' emphasis on the first two stages of design, as described in Section 1.2), students were not required to perform the "Preliminary Design" stage. Despite this, many students opted to create CAD representations of their final design solution.

\section{Preliminary Results}

In its first semester implementation, the ROXIE project paired 185 first-year student design teams with 87 community partners. In this section, the authors present some preliminary results of this effort.

\subsection{Example Projects}

A small sample of the many design projects that have been addressed by student teams via ROXIE are presented in Table 3.

It is important to note the variety of projects that the ROXIE project accommodates: not all projects are dominated by a single engineering discipline, and students are not engaged solely in product design; several projects involve the design of processes or plans, and thus help broaden the students' understanding of the applicability of the engineering design process. 
Table 3. Example ROXIE Design Projects

\begin{tabular}{|c|c|}
\hline Community Organization & Project Description \\
\hline $\begin{array}{l}\text { Community Economic } \\
\text { Development Organization }\end{array}$ & $\begin{array}{l}\text { Students designed a systematic process for volunteers to follow in future computer } \\
\text { refurbishing efforts. }\end{array}$ \\
\hline Boy Scouts & $\begin{array}{l}\text { Students redesigned an existing outdoor amphitheater. This included considerations } \\
\text { of layout, construction materials, and a means of anchoring seating to the hillside. }\end{array}$ \\
\hline Food Bank & $\begin{array}{l}\text { Students designed a device that would assist volunteers with transporting canned food } \\
\text { from the building's basement to its distribution floor. }\end{array}$ \\
\hline Humane Society & Students designed tip-proof feeding bowls for the dog kennels. \\
\hline March of Dimes & Students designed instructional materials and methods for the organizations' clients \\
\hline Faith-based Organizations & Students designed a system to control water runoff from the building site \\
\hline Campus Rescue Squad & Students designed a custom workbench for the ambulance maintenance crew. \\
\hline Community Transit System & $\begin{array}{l}\text { Students designed an efficient route and method for volunteers to follow when } \\
\text { cleaning bus stops. }\end{array}$ \\
\hline
\end{tabular}

\subsection{Community Partner Response}

Community partners' responses to the ROXIE Project were overwhelmingly positive. The authors received several unsolicited memos expressing their perceived benefits of being involved with the project. Primarily, community partners commented on the benefit that they received from the students' work.

"Now that we have our report from our ROXIE team, we will begin immediately to apply for grants to fund our outdoor classrooms. It is very helpful and timesaving to have the detailed design and expenses in hand." Assistant Principal, Elementary School

"Thanks to the hard work of our ROXIE team, 28 young people working on their GED's already have a computer to help them with their studies, which will help ensure their success with passing this test." Executive Director, community economic development organization

"I just wanted to express my thanks for the opportunity to work with your Engineering students. ... The plans that were submitted as part of their final report will most likely be implemented as soon as we are able to work out the logistics of the move. ... What a great benefit to the museum this assignment was! It is so good to see the University helping the community in these ways." Executive Director, Museum and Regional Art Center

Further evidence of the community organizations' positive experience with the ROXIE project is the frequency of repeat participants it has had thus far during its three-semester run. Community partners have reported that the enthusiasm, drive, and fresh perspective of the students have lifted their employees' spirits and attitudes; thus they already see ROXIE as a part of their routine operations each semester and are expressing interest in furthering the partnership.

"We plan to implement as many projects as possible developed by our ROXIE teams. We are looking forward to a continued relationship with engineering students at Virginia Tech-possibly even working on more advanced projects as seniors." Director, Girl Scouts 
Many previous campus/community project interactions had left the community feeling used as research subjects. The ROXIE project seemed to not only changed that perception, but also demonstrated to the community that the university is willing and able contribute to the community in solving their real design problems.

\subsection{Student Response}

In general, the students also responded well to the ROXIE project. Excerpts from their learning essays (submitted at the closure of the project; Table 1) suggest that they appreciated the opportunity to contribute to the community while learning and practicing engineering design:

"It is easy for students to struggle in finding a purpose for studying engineering during their freshmen year. ROXIE was an experience that allowed students to make their studies worthwhile, share their hard work with the community, and develop their engineering design skills and communication skills."

"Being outdoors and doing a good deed for several young kids made this project an excitement from the start."

In addition, many students commented on the impact that the ROXIE project had on their understanding of engineering design:

"(at) the beginning of the project I felt overwhelmed and flustered ... I felt unprepared to do any good ... However, by the middle of the project I was more comfortable with the idea of working with a real community partner and not a theoretical person."

"I thought I was going to design an object within a group and have competition with other groups. However (through ROXIE) I recognized design is more than that and it is a process of finding and solving these problems."

"The ROXIE project was a unique experience that helped me to improve on my design abilities and also showed me what the future as an engineer would be like."

As can be expected, not all student responses were positive. Student expressions of dissatisfaction tended to fall in three themes: concern that their project was not "true engineering," being partnered with an incommunicative community partner, and dislike of the systematic design process. It is believed that these three general criticisms are primarily derived from the infrequency of expert design mentoring - a drawback of offering a service-learning project at such a large scale. 


\section{Closure \& Future Work}

In this paper the authors detail the creation of a new design project experience for a first-year engineering course featuring a large enrollment: "Real Outreach eXperiences In Engineering" (ROXIE). Student teams involved in the ROXIE project are partnered with a community organization and are tasked with identifying and solving a need of the organization through engineering design. Specifically, students are asked to first volunteer with their partner organization, then to identify an appropriate design problem, and finally, to offer a solution by progressing through a systematic design process.

The concept of merging a service-learning activity with engineering design pedagogy was deemed an appropriate choice for a first-year design project as it satisfied the diverse needs of the course enrollment: 900 students from multiple engineering disciplines. The ROXIE project provides a "real world" context in which students can gain experience in practicing engineering design and implementing a structured design methodology. Most importantly, the ROXIE project provides an opportunity for students to gain a better understanding of how to frame an engineering design problem; a necessary skill for all engineering disciplines (Section 1.2).

While preliminary feedback from both community partners (Section 4.2) and students (Section 4.3) is positive, there are several opportunities for future work. In the context of augmenting the ROXIE implementation strategy, the authors are currently exploring reducing the number of participating community organizations (and thus feature more student teams working on the same design problem). Doing so will reduce some administrative overhead, provide multiple design solutions to the community partners, and somewhat alleviate the troubles associated with trying to mentor teams that are navigating dozens of different design projects. In the context of research, the authors wish to explore the effect of providing students with direct customer interaction. Specifically the authors would like to assess how first-year student interaction with a real customer can affect their motivation, self-efficacy, and design learning.

\section{Acknowledgements}

The authors wish to acknowledge Michele James-Deramo, director of the Virginia Tech Center for Student Engagement \& Community Partnerships, for her involvement in the planning stages of the ROXIE project. The authors also wish to offer their gratitude to Andy Morikawa, the Executive Director of The Community Foundation of the New River Valley, for his input into the development of the ROXIE program and his involvement with the project kickoff event (Section 3.2). 


\section{References}

${ }^{1}$ Boyer Commission, 1998, "Reinventing Undergraduate Education: A Blueprint for America's Research Universities," http://naples.cc.sunysb.edu/Pres/boyer.nsf/ (accessed February, 2009).

2 ABET, 2008, Criteria for Accrediting Engineering Programs, The Engineering Accreditation Commission of The Accreditation Board for Engineering and Technology, http://www.abet.org/Linked DocumentsUPDATE/Criteria and PP/E001 08-09 EAC Criteria 12-04-07.pdf (accessed February, 2009).

${ }^{3}$ Friedman, Thomas H., 2005, The World is Flat: A Brief History of the Twenty-First Century, New York: Farrar, Straus and Giroux.

${ }^{4}$ Dym, C. L., 1994, "Teaching Design to Freshmen: Style and Content," Journal of Engineering Education, Vol. 83, No. 4, pp. 303-310.

5 Thompson, M. \& Oakes, W., 2005, “A Qualitative Investigation of a First-Year Engineering Service-Learning Program," Proceedings of the ASEE 2005 ASEE Annual Conference, Portland, OR.

${ }^{6}$ Corporation for National and Community Service, 1993, National and Community Service Trust Act of 1993, http://www.nationalservice.org/pdf/cncs_statute_1993.pdf (accessed February, 2009).

${ }^{7}$ Eyler, J. \& D. Giles, 1999, Where's the Learning in Service-Learning?, San Francisco: Jossey-Bass.

${ }^{8}$ Vaughn, R. L., Seifer, S. D., 2004, "Quick Guide: Service-Learning in Engineering Education," Corporation for National and Community Service, http://www.servicelearning.org/instant_info/fact_sheets/he_facts/eng_ed/ (accessed February, 2009).

${ }^{9}$ Duffy, J., Tsang, E., and Lord, S., 2000, “Service Learning in Engineering: What, Why, and How?,” Proceedings of the ASEE 2000 Annual Conference, St. Louis, Mo.

${ }^{10}$ Lima, M. \& Oakes, W., 2006, Service-Learning: Engineering in Your Community, Okemos, MI: Great Lakes Press.

${ }^{11}$ Coyle, E. J., Jamieson, L. H., Oakes, W. C., 2005, "EPICS: Engineering Projects in Community Service," International Journal of Engineering Education, Vol. 21, No.1, pp. 139-150.

12 Hobson, R.S, 2000, "Service-Learning as an Educational Tool in an Introduction to Engineering Course," Proceedings of the ASEE 2000 Annual Conference, St. Louis, Missouri.

${ }^{13}$ Meadows, L., Jarema, S., 2006, “An Evaluation of the Impact of a Service Learning Project in a Required First Year Engineering Course,” Proceedings of the ASEE 2006 Annual Conference, Chicago, IL.

14 Oakes, W. \& Thompson, M., 2005, "Institutionalizing Service-Learning into a First-Year Engineering Curriculum," Proceedings of the ASEE 2005 ASEE Annual Conference, Portland, OR.

15 VT CSECP, 2009, "Center for Student Engagement and Community Partnership," http://www.vtserves.vt.edu/ (accessed February, 2009).

${ }^{16}$ VT-ENGAGE, 2009, “VT-ENGAGE: Remember, Serve, Learn,” http://www.engage.vt.edu, (accessed February, 2009).

${ }^{17}$ Dym, C. L. and Litte, P., 2009, Engineering Design: A Project-Based Introduction, $3^{\text {rd }}$ Edition, Hoboken, NJ: John Wiley \& Sons, Inc. 